\title{
STRENGTH AND BALANCE DEFICITS AFFECTING PATIENT SATISFACTION WITH TOTAL KNEE REPLACEMENTS
}

original paper

( ) University School of Physical Education in Wroclaw

DOI: https://doi.org/10.5114/hm.2021.103294

\author{
KEVIN ALAN VALENZUELA ${ }^{1}$, LAUREN ELIZABETH SCHROEDER ${ }^{2}$, \\ JOSHUA TRUEBLOOD WEINHANDL ${ }^{2}$, HAROLD EARL CATES ${ }^{3}$, SONGNING ZHANG ${ }^{2}$ \\ ${ }^{1}$ California State University, Long Beach, CA, USA \\ ${ }^{2}$ University of Tennessee, Knoxville, TN, USA \\ ${ }^{3}$ Tennessee Orthopaedic Clinics, Knoxville, TN, USA
}

\section{ABSTRACT}

Purpose. Patient satisfaction with total knee replacement has been commonly assessed with self-reported surveys. Up to $19 \%$ of patients were dissatisfied with total knee replacement outcomes; however, very little is known about their objective physical abilities. Restoring knee strength is crucial for an increase in functional abilities. Improved balance is an essential measure of total knee replacement success. However, it is unknown how dissatisfied patients differ from satisfied ones with respect to strength and balance abilities. The purpose of this study was to examine how knee flexor and extensor strength and balance abilities differed for dissatisfied total knee replacement patients compared with satisfied patients and healthy controls.

Methods. The study involved 9 dissatisfied and 15 satisfied total knee replacement patients and 15 healthy controls. Participants performed isokinetic knee flexion and extension tests at $60 \%$ and $180 \%$ s using an isokinetic dynamometer. Bilateral and unilateral static and dynamic balance trials employed a Biodex Balance System. Stair ascent/descent tests and a chair rise test served to examine speed of activity.

Results. Dissatisfied patients showed reduced peak extension $(180 \%$ s) and flexion $(60 \%$ s) torque compared with satisfied patients. No balance differences were evident, although an increased percentage of dissatisfied patients were unable to complete the static and dynamic unilateral balance tests. Stair ascent and descent times and pain levels were increased in the dissatisfied group.

Conclusions. Strength increase may provide a more symmetrical movement pattern and better function. The inability to balance and longer functional test times indicate reduced functional ability and continuous pain.

Key words: total knee replacement, arthroplasty, isokinetic strength, balance

\section{Introduction}

Patient satisfaction rates for the total knee replacement (TKR) procedure turn out to be as low as $81 \%$ when self-reported through survey measurements $[1,2]$. This leaves a significant portion of the TKR population as dissatisfied with the replacement outcomes. Post-operative pain [3] and functional limitations [4] are commonly self-reported by dissatisfied patients on surveys related to the TKR procedure. This often results in decreased performance in common clinical tests (such as timed up-and-go or sit-to-stand) when compared with healthy controls [5, 6]. These tests are often seen as a defining point for 'success' of the operation as they are deemed to determine the restoration of function for the replaced joint. However, these test results do not sufficiently explain why the TKR patients are dissatisfied with the TKR outcomes. While these tests are easily administered, they do not explain the physical limitations experienced by the dissatisfied TKR patients, thereby suggesting that additional research into the mechanisms of dissatisfaction is needed. Physical testing of strength, balance, and functional abilities may help to provide a link between the more

Correspondence address: Songning Zhang, University of Tennessee, 1914 Andy Holt Ave., Knoxville, TN 37996, USA, e-mail: szhang@utk.edu

Received: October 18, 2019

Accepted for publication: October 5, 2020

Citation: Valenzuela KA, Schroeder LE, Weinhandl JT, Cates HE, Zhang S. Strength and balance deficits affecting patient satisfaction with total knee replacements. Hum Mov. 2021;22(4):83-92; doi: https://doi.org/10.5114/hm.2021.103294. 
easily administered survey and functional tests to what the objective physical limitations are that may be present in the dissatisfied patient population.

Current research on dissatisfied patients who undergo TKR has largely focused on survey data and limited testing of physical functions and capacities [7-9]. Much of this research has been conducted by using subjective data to assess physical function, such as self-reported physical function as measured through survey data. Some of the research which utilized these surveys has shown reduced self-reported physical function for dissatisfied TKR patients [8, 9]. The limited physical testing has consisted of simple functional tasks such as a 6-minute walk test or sit-to-stand test [7]. Survey data have shown increased difficulty in certain activities for dissatisfied TKR populations [10] but have failed to provide additional insight into the difficulty magnitude and mechanisms. For example, stair climbing has been suggested as a difficult activity for patients with knee pain and instability [11]. However, the physical mechanisms causing these difficulties are unknown. Increased strength and balance are needed to successfully perform more demanding daily activities such as navigating stairs. Therefore, information about strength and balance for dissatisfied TKR populations may provide insight into their difficulties.

An increase in knee strength levels following a TKR operation is crucial for a return to more normal function levels. Knee extensor strength is most commonly assessed when determining the adequacy of strength levels in TKR patients. However, the flexors are also important for knee stabilization as the co-contraction of the flexors and extensors helps to provide dynamic knee stability during dynamic movement such as walking, warranting their examination as well. Significant reductions in extensor and flexor strength are evident early ( 1 month post-operatively) in the rehabilitation process, with up to $60 \%$ deficits observed compared with pre-operative levels [12]. By 6 months post-operation, both muscle groups show significant increases in strength [13]. However, TKR patients do not normally achieve strength levels equal to those of healthy controls, with deficits still present 12 months after surgery in the replaced limb but no difference in the non-replaced limb compared with healthy controls [14]. While most studies examine strength levels within 1 year post-operatively, one study has shown reduced peak extensor and flexor torques at $180 \% \mathrm{~s}$ at an average of 98 months post-operatively [15], suggesting that reduced strength still persists over time. Multiple studies involving isokinetic strength testing for this patient group have commonly employed testing speeds of $60 \% \mathrm{~s}$ and $180 \%$ [ [15-17]. Previous research has shown an increase in quadriceps strength as assessed with a handheld dynamometer [18]. In that study, the researchers differentiated 2 groups of knee replacements based on a single-radius versus a multi-radius TKR. The single-radius group presented increased quadriceps strength, increased knee range of motion (ROM), and increased patient satisfaction compared with the multi-radius group [18]. However, patient satisfaction is unknown for each TKR patient group, thereby not providing the differences between these 2 groups. There is a lack of research on strength with respect to TKR patient dissatisfaction and on the role that knee strength plays in TKR patient dissatisfaction. Post-operative strength deficits may be more pronounced in dissatisfied patients, which may impair functional ability.

Balance is an additional measure of success for TKR operations and return to normal daily activities as falls can be detrimental to the elderly population, which includes the majority of the TKR population [19]. TKR patients have been shown to exhibit decreased stability after surgery compared with healthy controls [20]. Improvements in balance have been associated with improvements in functional capacities commonly tested, such as stair climb, 30-second chair rise, timed up-and-go, and gait speed [21]. Strength and balance have often been measured together as a means of using strength gains to explain changes in balance abilities. Increased knee extensor strength coupled with increased gait speed has been linked to increased anteroposterior balance (measured through the range of the anteroposterior trajectory of centre of pressure), but increased knee extensor strength with reduced gait speed has been linked to a reduced anteroposterior balance [22]. However, it was shown that peak torque did not predict single leg static balance performance [23]. As with strength data, there is a lack of balance data with respect to patient dissatisfaction.

To our knowledge, no studies have been conducted on the strength and balance abilities of dissatisfied TKR patients. Therefore, the purpose of this study was to examine how the knee concentric muscle strength and balance abilities of both the replaced and non-replaced limbs in dissatisfied TKR patients compared with those among satisfied TKR patients and healthy controls. A secondary purpose was to compare dissatisfied TKR patients with satisfied TKR patients using more frequently applied assessment tools (surveys and functional tests) to determine if changes in strength and balance coincided with the changes pre- 
viously seen in the surveys and functional tests. It was hypothesized that dissatisfied TKR patients would show deficits of knee extensor and flexor strength and balance abilities in their replaced limb compared with their non-replaced limbs and compared with satisfied TKR patients and healthy controls. It was also hypothesized that the dissatisfied patients would present decreased functional abilities and reduced self-reported functional abilities on subjective surveys measurements.

\section{Material and methods}

\section{Subjects}

This study was conducted as a level III case-control study. All subjects were informed of potential risks and benefits of the study. An a priori power analysis using the $G^{*}$ Power software showed that a minimum of 9 participants per group were needed with a beta of 0.8 at an alpha level of 0.05 . As this data set was a part of a larger study, the power analysis was based on knee extension moment data during a stair ascent task [24]. Nine dissatisfied TKR participants (34.6 \pm 14.3 months from surgery), 15 satisfied TKR participants $(29.3 \pm 12.8$ months from surgery), and 15 healthy participants were involved in this study (Table 1). TKR participants were recruited from a local orthopaedic clinic over a 15-month period. The inclusion criteria for TKR patients were the presence of a unilateral TKR performed by a single surgeon, a period of at least 12 months but less than 60 months from surgery, and age of 50-75 years. Exclusion criteria were any additional lower extremity joint replacements, any additional diagnosed hip, knee, or ankle osteoarthritis, body mass index greater than 38 , or neurological diseases. TKR patients were asked, 'How satisfied are you with your total knee replacement?'
The available responses were 'very dissatisfied,' 'dissatisfied,' 'neutral,' 'satisfied,' or 'very satisfied'. Neutral responses were excluded. 'Very dissatisfied' or 'dissatisfied' responses were placed into the dissatisfied group and 'satisfied' or 'very satisfied' were placed into the satisfied group. Seven other dissatisfied patients were recruited, but had to be excluded from the study as they did not meet the inclusion criteria (4 had bilateral TKR and $3 \mathrm{had}$ a body mass index above the threshold for inclusion). The healthy control group was recruited with the same exclusion criteria as the TKR groups.

\section{Procedures}

At the beginning of the testing session, all participants completed the Western Ontario and McMaster Universities survey (WOMAC) for both knees [25]. TKR participants then completed the Forgotten Joint Score questionnaire [26]. After completing all forms and surveys, the subjects performed a 5-minute walking warm-up on a treadmill at a self-selected speed. Passive knee ROM was then measured in both knees while participant was lying supine on a treatment table [24]. The subjects performed 2 trials of a stair ascent/descent test using an 11-step staircase and a chair rise test, with best times being reported. Six test conditions of bilateral and unilateral postural static and dynamic (at level 11 setting, with 1 being the most difficult and 12 being the least difficult) stability tests were carried out. Participant's feet were placed in accordance with the instruction of the balance system. The individuals performed 3 trials of 20 seconds per condition (per manual specifications on time duration of each trial). One practice trial per condition and a rest period of 30 seconds between trials were given. A trial was repeated if the participant grabbed the handrail

Table 1. Descriptive statistics, functional tests, and survey data

\begin{tabular}{lcccl}
\hline Characteristics & Dissatisfied & Satisfied & Healthy & $p$ \\
\hline Age (years) & $68.0 \pm 4.2^{\mathrm{A}}$ & $66.6 \pm 6.3^{\mathrm{A}}$ & $60.7 \pm 9.2$ & $0.0034^{*}$ \\
Height $(\mathrm{m})$ & $1.69 \pm 0.07$ & $1.76 \pm 0.10$ & $1.75 \pm 0.09$ & 0.1280 \\
Weight $(\mathrm{kg})$ & $80.99 \pm 18.59$ & $90.19 \pm 16.98$ & $77.74 \pm 11.75$ & 0.0944 \\
Body mass index $\left(\mathrm{kg} / \mathrm{m}^{2}\right)$ & $28.13 \pm 4.61$ & $28.85 \pm 4.26$ & $25.33 \pm 3.34$ & 0.0563 \\
Months from surgery & $34.6 \pm 14.3$ & $29.3 \pm 12.8$ & $\mathrm{NA}$ & 0.3598 \\
Forgotten Joint Score (replaced limb) & $21.53 \pm 16.04^{\mathrm{B}}$ & $67.78 \pm 27.76$ & $\mathrm{NA}$ & $0.0002^{*}$ \\
Chair rise (s) & $18.43 \pm 7.26$ & $16.84 \pm 5.45$ & $15.01 \pm 4.21$ & 0.3327 \\
Stair ascent $(\mathrm{s})$ & $5.50 \pm 1.93^{\mathrm{AB}}$ & $4.30 \pm 0.79$ & $4.06 \pm 0.68$ & $0.0117^{*}$ \\
Stair descent $(\mathrm{s})$ & $5.93 \pm 2.91^{\mathrm{AB}}$ & $3.98 \pm 0.60$ & $3.68 \pm 0.50$ & $0.0021^{*}$ \\
\hline
\end{tabular}

NA - not applicable

A different from healthy group, ${ }^{\text {B }}$ different from satisfied group, ${ }^{*} p$ values significant at 0.05 
or required the investigator to catch them from falling. All balance test conditions were tested in a randomized order. Postural stability tests were performed by using a balance system (Biodex Balance System SD, Biodex Medical Systems, Shirley, USA), sampling at a rate of $20 \mathrm{~Hz}$. The visual feedback of centre of pressure traces was provided to participants during practice and test trials, giving them a target goal to maintain the centre of pressure in the centre of the grid. The subjects were instructed not to lock their knees out but were provided no instructions as to the level of knee flexion they should have.

After the completion of balance tests, participants completed isokinetic strength tests of the knee flexors and extensors. Strength tests were performed last to minimize the effect of fatigue from maximum effort muscle action on the other tests. Following a practice round of 2 sub-maximum and 1 maximum effort trials, participants performed 3 maximum effort trials of knee flexion and extension, at 2 different speeds $(60 \%$ s and $180 \%$ s). Knee flexion and extension repetitions were tested in succession at each speed for each leg. A rest period of 2 minutes was given between conditions. The speed conditions were randomized. Concentric knee extension and flexion muscle strength tests were performed with an isokinetic dynamometer (System 4, Biodex Medical Systems, Shirley, USA) at speeds of $60 \%$ s and $180 \%$ s. A $0-10$ numerical pain visual analogue scale was used to assess pain level after the tests in both knees for TKR participants and healthy participants for all conditions and tests.

\section{Data analyses}

Overall, mediolateral, and anteroposterior stability indices were calculated. With the centre of balance point defined as $(0,0)$ of the $X$ and $Y$ coordinate of the system, $\mathrm{X}$ and $\mathrm{Y}$ coordinate values were recorded at each sampling point $(20 \mathrm{~Hz})$. During the dynamic balance trials (level 11 was the dynamic level utilized in this testing), $\mathrm{X}$ and $\mathrm{Y}$ coordinate data were scaled at $1 / 100^{\circ}$, up to $20^{\circ}$ of the test platform tilt. The $X$ and $Y$ coordinates represent mediolateral (X) and anteroposterior $(\mathrm{Y})$ deviations from the centre of the balance surface. The overall stability index (OSI) was calculated as:

$$
O S I=\sqrt{\frac{\Sigma(X)^{2}-\Sigma(Y)^{2}}{N}}
$$

where $\mathrm{X}$ is the mediolateral coordinate, $\mathrm{Y}$ is the anteroposterior coordinate, and $N$ is the number of data points sampled. The mediolateral stability index (MLSI) and anteroposterior stability index (APSI) were calculated with the following equations:

$$
\begin{aligned}
& M L S I=\sqrt{\frac{\Sigma(X)^{2}}{N}} \\
& A P S I=\sqrt{\frac{\Sigma(Y)^{2}}{N}}
\end{aligned}
$$

Increased balance abilities were defined as the OSI, MLSI, and APSI being smaller numbers. The age-dependent normal stability index ranges for individuals aged 54-71 years were 1.79-3.35 (Biodex Balance System SD Reference Manual). There is no specific value to indicate what a 'good' score is, as this range provides only a normative value for individuals in this age range.

A customized MATLAB script (MathWorks, Natick, USA) calculated strength-related variables, including peak torque and torque loading rate (time to peak torque).

\section{Statistical analyses}

A $2 \times 3$ (limb $\times$ group) mixed model analysis of variance (ANOVA, $p<0.05$ ) using SAS software (version 9.4, Cary, USA) was performed to detect differences between limbs and groups for unilateral balance, strength variables, and WOMAC. When the ANOVA results revealed a significant interaction or main effect, pairwise $t$-tests were used to compare means with adjusted $p$ values of 0.00625 . Post-hoc comparisons were only made between the TKR replaced and healthy dominant limbs and TKR non-replaced limbs against the healthy non-dominant limbs. This was performed under the assumption that any differences between the dominant and non-dominant limb were random and small when present in the healthy population. A one-way (3 groups) ANOVA $(p<0.05)$ was performed on demographic, survey, bilateral balance, and functional test data to test for differences between the 3 groups. If a significant interaction was present, pairwise comparisons were made with an adjusted $p$ value of 0.0167 . The respective adjustments to the $p$ values for both the $2 \times 3$ and the $1 \times 3$ ANOVA were based on the amount of post-hoc comparisons being performed.

\section{Ethical approval}

The research related to human use has complied with all the relevant national regulations and institutional policies, has followed the tenets of the Declara- 
tion of Helsinki, and has been approved by the University of Tennessee Institutional Review Board.

\section{Informed consent}

Informed consent has been obtained from all individuals included in this study.

\section{Results}

Specific numerical results for the anthropometric data, Forgotten Joint Score, and functional test scores can be found in Table 1. Post-hoc tests revealed that the dissatisfied group had increased stair ascent ( $p=$ $0.0148)$ and descent $(p=0.0031)$ times compared with both the satisfied and healthy groups (Table 1). The dissatisfied group reported increased pain in their replaced limb compared with other groups and respective limbs during all 3 tests $(p<0.0148$ for all tests, see Table 5). WOMAC and passive knee ROM can be found in Table 2. Significant interactions revealed that the dissatisfied group had decreased passive knee ROM in the replaced limb compared with their nonreplaced limb and healthy group $(p<0.0015$ for both tests) but no difference was observed from the replaced limb of the satisfied group (Table 2). Significant interactions were present for all WOMAC subscales and total scores (Table 2). The dissatisfied group reported increased total WOMAC and subscale scores in their replaced limb compared with their non-replaced limb and satisfied and healthy groups. The satisfied group reported increased WOMAC total and physical function scores for both limbs as well as increased stiffness in their replaced limb compared with the healthy group.

Peak isokinetic knee flexion and extension torque and loading rates can be found in Table 3. Significant interactions were present for peak extension torque at $180 \%$ s and flexion at both $60 \%$ s and $180 \%$ s (Table 3). Post-hoc comparisons showed that the dissatisfied group replaced limb had lower peak extension torque at $180 \%$ s than their non-replaced limb and both satisfied and healthy groups ( $p<0.0051$ for all tests). Peak torque during the $60 \%$ flexion test was reduced in the replaced limb of the dissatisfied group compared with that of the satisfied group $(p=0.0168)$. Additionally, there was a limb main effect for the $60 \%$ s exten-

Table 2. WOMAC scores (100-mm VAS) and passive knee ROM $\left(^{\circ}\right)$

\begin{tabular}{|c|c|c|c|c|c|c|c|}
\hline Parameters & $\begin{array}{c}\text { Dissatisfied } \\
\text { replaced }\end{array}$ & $\begin{array}{c}\text { Dissatisfied } \\
\text { non-replaced }\end{array}$ & $\begin{array}{l}\text { Satisfied } \\
\text { replaced }\end{array}$ & $\begin{array}{l}\text { Satisfied non- } \\
\text { replaced }\end{array}$ & $\begin{array}{l}\text { Healthy } \\
\text { dominant }\end{array}$ & $\begin{array}{c}\text { Healthy non- } \\
\text { dominant }\end{array}$ & $\begin{array}{c}\text { Interaction } \\
p\end{array}$ \\
\hline WOMAC total ${ }^{\# *}$ & $794.9 \pm 484.2^{\mathrm{ABC}}$ & $67.2 \pm 64.5$ & $251.2 \pm 179.2^{\mathrm{C}}$ & $196.5 \pm 175.8^{\mathrm{C}}$ & $29.9 \pm 73.5$ & $18.5 \pm 40.2$ & $<0.0001 * *$ \\
\hline WOMAC physical function ${ }^{\# *}$ & $525.2 \pm 323.9^{\mathrm{ABC}}$ & $38.3 \pm 30.3$ & $179.2 \pm 141.3^{\mathrm{C}}$ & $144.5 \pm 131.1^{\mathrm{C}}$ & $16.1 \pm 39.3$ & $12.5 \pm 26.8$ & $<0.0001 * *$ \\
\hline WOMAC stiffness ${ }^{\# *}$ & $76.1 \pm 58.3^{\mathrm{ABC}}$ & $8.2 \pm 8.6$ & $38.1 \pm 41.8^{\mathrm{C}}$ & $26.8 \pm 44.4$ & $6.5 \pm 18.3$ & $2.9 \pm 6.3$ & $0.0007 * *$ \\
\hline WOMAC pain"** & $193.7 \pm 138.6^{\mathrm{ABC}}$ & $20.7 \pm 34.0$ & $33.9 \pm 30.1$ & $25.1 \pm 22.8$ & $7.3 \pm 17.3$ & $3.1 \pm 7.6$ & $<0.0001^{* *}$ \\
\hline Passive knee $\mathrm{ROM}^{\#}$ & $118.3 \pm 7.4^{\mathrm{AC}}$ & $131.0 \pm 10.4$ & $122.9 \pm 10.5^{\mathrm{AC}}$ & $134.4 \pm 9.3$ & $134.3 \pm 13.5$ & $135.4 \pm 13.4$ & $0.0001 * *$ \\
\hline
\end{tabular}

WOMAC - Western Ontario and McMaster Universities survey, VAS - visual analogue scale, ROM - range of motion

${ }^{\mathrm{A}}$ significantly different from contralateral leg of same total knee replacement group, ${ }^{\mathrm{B}}$ significantly different from same leg of satisfied total knee replacement group, ${ }^{\mathrm{C}}$ significantly different from same leg of healthy group, ${ }^{\#}$ limb main effect,

${ }^{*}$ group main effect, ${ }^{* *} p$ values significant at 0.05

Table 3. Peak isokinetic knee extension and flexion torque (Nm) and extension and flexion loading rate (LR; Nm/s)

\begin{tabular}{|c|c|c|c|c|c|c|c|}
\hline Parameters & $\begin{array}{l}\text { Dissatisfied } \\
\text { replaced }\end{array}$ & $\begin{array}{c}\text { Dissatisfied } \\
\text { non-replaced }\end{array}$ & $\begin{array}{l}\text { Satisfied } \\
\text { replaced }\end{array}$ & $\begin{array}{c}\text { Satisfied } \\
\text { non-replaced }\end{array}$ & $\begin{array}{l}\text { Healthy } \\
\text { dominant }\end{array}$ & $\begin{array}{c}\text { Healthy } \\
\text { non-dominant }\end{array}$ & $\begin{array}{c}\text { Interaction } \\
p\end{array}$ \\
\hline Extension at $60 \% \mathrm{~s}^{\#}$ & $85.2 \pm 30.9$ & $110.5 \pm 41.1$ & $118.3 \pm 39.1$ & $132.5 \pm 41.3$ & $117.6 \pm 36.4$ & $122.1 \pm 39.3$ & 0.0664 \\
\hline Flexion at $60 \% \mathrm{~s}$ & $48.0 \pm 15.9^{\mathrm{B}}$ & $52.4 \pm 19.8$ & $64.3 \pm 21.1$ & $67.1 \pm 21.0$ & $63.2 \pm 13.0$ & $58.0 \pm 17.1$ & $0.0168 * *$ \\
\hline Flexion at $180^{\circ} / \mathrm{s}^{*}$ & $34.4 \pm 13.7$ & $33.7 \pm 15.3^{\mathrm{B}}$ & $48.5 \pm 19.0^{\mathrm{A}}$ & $57.0 \pm 21.4$ & $47.7 \pm 14.8$ & $45.8 \pm 12.7$ & $0.0020 * *$ \\
\hline Extension LR at $60 \% \mathrm{~s}$ & $151.0 \pm 114.0$ & $139.2 \pm 68.9$ & $169.1 \pm 95.9$ & $189.4 \pm 73.4$ & $164.8 \pm 76.2$ & $158.3 \pm 61.9$ & 0.6898 \\
\hline Flexion LR at $180^{\circ} / \mathrm{s}$ & $185.0 \pm 84.0$ & $171.0 \pm 111.1$ & $288.7 \pm 184.2$ & $320.2 \pm 224.0$ & $295.5 \pm 213.9$ & $224.9 \pm 203.2$ & 0.2566 \\
\hline
\end{tabular}

\footnotetext{
${ }^{\mathrm{A}}$ significantly different from contralateral leg of same total knee replacement group, ${ }^{\mathrm{B}}$ significantly different from same leg of satisfied total knee replacement group, ${ }^{\mathrm{C}}$ significantly different from same leg of healthy group, ${ }^{\#}$ limb main effect,

* group main effect, ${ }^{* *} p$ values significant at 0.05
} 
K. Valenzuela et al., Total knee replacement: strength and balance

sion test, with the replaced limbs having lower peak torque than the non-replaced. However, there were no differences in loading rate for any of the tested speeds. Significant interactions revealed that the dissatisfied group reported increased knee pain in their replaced limb during the $60 \% \mathrm{~s}(p=0.0018)$ and $180 \% \mathrm{~s}(p=$ $0.0011)$ tests compared with their non-replaced limb and satisfied and healthy groups (see Table 5). A group main effect was present during the non-replaced $60 \% \mathrm{~s}$ test, with the dissatisfied group showing increased pain compared with the satisfied and healthy groups.

OSI, APSI, and MLSI scores can be found in Table 4. There were no interactions for any of the balance vari- ables (Table 4). A limb main effect was observed for MLSI during the static condition, with replaced limbs having increased mediolateral sway during unilateral stance. What is of interest to note, approximately $33 \%$ of dissatisfied participants were unable to complete unilateral static balance trials on either limb while $13 \%$ of the satisfied group were unable to do so on their replaced limb and $20 \%$ on their non-replaced limb. During the dynamic unilateral tests, these numbers increased to $56 \%$ of dissatisfied participants and $27 \%$ of satisfied participants on both limbs. All healthy individuals completed the test on the nondominant limb but $13 \%$ could not on their dominant

Table 4. Unilateral overall stability index (OSI), mediolateral stability index (MLSI), and anteroposterior stability index (APSI), as well as bilateral OSI, MLSI, and APSI stability indices (one-way ANOVA)

\begin{tabular}{|c|c|c|c|c|c|c|c|}
\hline Parameters & $\begin{array}{l}\text { Dissatisfied } \\
\text { replaced }\end{array}$ & $\begin{array}{c}\text { Dissatisfied } \\
\text { non-replaced }\end{array}$ & $\begin{array}{l}\text { Satisfied } \\
\text { replaced }\end{array}$ & $\begin{array}{c}\text { Satisfied } \\
\text { non-replaced }\end{array}$ & $\begin{array}{l}\text { Healthy } \\
\text { dominant }\end{array}$ & $\begin{array}{c}\text { Healthy } \\
\text { non-dominant }\end{array}$ & $\begin{array}{c}\text { Interaction } \\
p\end{array}$ \\
\hline Static OSI & $2.68 \pm 1.17$ & $3.20 \pm 1.35$ & $3.05 \pm 1.59$ & $2.21 \pm 1.46$ & $3.08 \pm 1.52$ & $1.71 \pm 0.81$ & 0.1314 \\
\hline Dynamic OSI & $2.23 \pm 0.57$ & $2.60 \pm 0.47$ & $2.55 \pm 0.81$ & $2.56 \pm 0.92$ & $2.38 \pm 0.52$ & $2.41 \pm 0.84$ & 0.8397 \\
\hline Static APSI & $1.55 \pm 0.90$ & $2.40 \pm 1.20$ & $1.72 \pm 1.36$ & $1.38 \pm 1.16$ & $1.50 \pm 1.26$ & $1.14 \pm 0.63$ & 0.2484 \\
\hline Dynamic APSI & $1.65 \pm 0.95$ & $2.38 \pm 0.39$ & $1.45 \pm 0.73$ & $1.61 \pm 0.85$ & $1.73 \pm 0.81$ & $1.49 \pm 0.80$ & 0.1316 \\
\hline Static MLSI ${ }^{\#}$ & $1.95 \pm 1.04$ & $1.80 \pm 0.95$ & $2.20 \pm 1.20$ & $1.39 \pm 1.14$ & $2.35 \pm 1.28$ & $1.03 \pm 0.55$ & 0.2598 \\
\hline Dynamic MLSI & $0.90 \pm 0.88$ & $0.93 \pm 0.28$ & $1.64 \pm 1.12$ & $1.50 \pm 1.18$ & $1.27 \pm 0.51$ & $1.57 \pm 0.85$ & 0.7045 \\
\hline Static OSI bilateral & \multicolumn{2}{|c|}{$1.36 \pm 1.86$} & \multicolumn{2}{|c|}{$0.90 \pm 0.86$} & \multicolumn{2}{|c|}{$1.40 \pm 1.36$} & 0.5498 \\
\hline Dynamic OSI bilateral & \multicolumn{2}{|c|}{$1.69 \pm 0.53$} & \multicolumn{2}{|c|}{$1.56 \pm 0.75$} & \multicolumn{2}{|c|}{$1.79 \pm 0.65$} & 0.6511 \\
\hline Static APSI bilateral & \multicolumn{2}{|c|}{$1.13 \pm 1.89$} & \multicolumn{2}{|c|}{$0.70 \pm 0.85$} & \multicolumn{2}{|c|}{$1.06 \pm 1.20$} & 0.6518 \\
\hline Dynamic APSI bilateral & \multicolumn{2}{|c|}{$1.24 \pm 0.54$} & \multicolumn{2}{|c|}{$1.21 \pm 0.79$} & \multicolumn{2}{|c|}{$1.39 \pm 0.74$} & 0.7786 \\
\hline Static MLSI bilateral & \multicolumn{2}{|c|}{$0.39 \pm 0.43$} & \multicolumn{2}{|c|}{$0.35 \pm 0.36$} & \multicolumn{2}{|c|}{$0.65 \pm 0.84$} & 0.3504 \\
\hline Dynamic MLSI bilateral & \multicolumn{2}{|c|}{$0.90 \pm 0.43$} & \multicolumn{2}{|c|}{$0.73 \pm 0.35$} & \multicolumn{2}{|c|}{$0.85 \pm 0.27$} & 0.4439 \\
\hline
\end{tabular}

\# limb main effect

Table 5. Pain for individual tests (0-10 Likert scale)

\begin{tabular}{|c|c|c|c|c|c|c|c|}
\hline Parameters & $\begin{array}{l}\text { Dissatisfied } \\
\text { replaced }\end{array}$ & $\begin{array}{c}\text { Dissatisfied } \\
\text { non-replaced }\end{array}$ & $\begin{array}{l}\text { Satisfied } \\
\text { replaced }\end{array}$ & $\begin{array}{c}\text { Satisfied } \\
\text { non-replaced }\end{array}$ & $\begin{array}{l}\text { Healthy } \\
\text { dominant }\end{array}$ & $\begin{array}{c}\text { Healthy } \\
\text { non-dominant }\end{array}$ & $\begin{array}{c}\text { Interaction } \\
p\end{array}$ \\
\hline Chair rise $\mathrm{e}^{\# *}$ & $1.44 \pm 2.00^{\mathrm{ABC}}$ & $0.00 \pm 0.00$ & $0.13 \pm 0.52$ & $0.13 \pm 0.52$ & $0.00 \pm 0.00$ & $0.00 \pm 0.00$ & $0.0013 * *$ \\
\hline Stair ascent ${ }^{\# *}$ & $1.56 \pm 1.94^{\mathrm{ABC}}$ & $0.00 \pm 0.00$ & $0.00 \pm 0.00$ & $0.00 \pm 0.00$ & $0.00 \pm 0.00$ & $0.00 \pm 0.00$ & $0.0001 * *$ \\
\hline Stair descent ${ }^{\# *}$ & $1.78 \pm 2.44^{\mathrm{ABC}}$ & $0.00 \pm 0.00$ & $0.00 \pm 0.00$ & $0.00 \pm 0.00$ & $0.00 \pm 0.00$ & $0.00 \pm 0.00$ & $0.0006 * *$ \\
\hline Bilateral static balance ${ }^{\# *}$ & $1.33 \pm 2.06^{\mathrm{ABC}}$ & $0.22 \pm 0.67$ & $0.00 \pm 0.00$ & $0.00 \pm 0.00$ & $0.00 \pm 0.00$ & $0.00 \pm 0.00$ & $0.0033 * *$ \\
\hline Bilateral dynamic balance ${ }^{\# *}$ & $0.78 \pm 1.56^{\mathrm{ABC}}$ & $0.00 \pm 0.00$ & $0.00 \pm 0.00$ & $0.00 \pm 0.00$ & $0.00 \pm 0.00$ & $0.00 \pm 0.00$ & $0.0257 * *$ \\
\hline Unilateral replaced static $^{\# *}$ & $1.56 \pm 2.46^{\mathrm{ABC}}$ & $0.22 \pm 0.67$ & $0.00 \pm 0.00$ & $0.00 \pm 0.00$ & $0.00 \pm 0.00$ & $0.00 \pm 0.00$ & $0.0064 * *$ \\
\hline Unilateral replaced dynamic ${ }^{\# *}$ & $0.78 \pm 1.56^{\mathrm{ABC}}$ & $0.00 \pm 0.00$ & $0.00 \pm 0.00$ & $0.00 \pm 0.00$ & $0.00 \pm 0.00$ & $0.00 \pm 0.00$ & $0.0257 * *$ \\
\hline Unilateral non-replaced static & $0.33 \pm 1.00$ & $0.00 \pm 0.00$ & $0.00 \pm 0.00$ & $0.00 \pm 0.00$ & $0.00 \pm 0.00$ & $0.07 \pm 0.26$ & 0.1508 \\
\hline Unilateral non-replaced dynamic ${ }^{\# *}$ & $0.78 \pm 1.56^{\mathrm{ABC}}$ & $0.00 \pm 0.00$ & $0.00 \pm 0.00$ & $0.00 \pm 0.00$ & $0.00 \pm 0.00$ & $0.00 \pm 0.00$ & $0.0257 * *$ \\
\hline Replaced $60 \% \mathrm{~s}^{\# *}$ & $1.67 \pm 2.5^{\mathrm{ABC}}$ & $0.00 \pm 0.00$ & $0.00 \pm 0.00$ & $0.00 \pm 0.00$ & $0.00 \pm 0.00$ & $0.00 \pm 0.00$ & $0.0018 * *$ \\
\hline Replaced $180^{\circ} / \mathrm{s}^{\# *}$ & $1.56 \pm 2.24^{\mathrm{ABC}}$ & $0.00 \pm 0.00$ & $0.00 \pm 0.00$ & $0.00 \pm 0.00$ & $0.00 \pm 0.00$ & $0.00 \pm 0.00$ & $0.0011 * *$ \\
\hline Non-replaced $60^{\circ} / \mathrm{s}^{*}$ & $0.78 \pm 1.56$ & $0.11 \pm 0.33$ & $0.00 \pm 0.00$ & $0.00 \pm 0.00$ & $0.00 \pm 0.00$ & $0.10 \pm 0.39$ & 0.0615 \\
\hline Non-replaced $180^{\circ} / \mathrm{s}$ & $0.78 \pm 1.56^{\mathrm{ABC}}$ & $0.00 \pm 0.00$ & $0.00 \pm 0.00$ & $0.07 \pm 0.26$ & $0.00 \pm 0.00$ & $0.07 \pm 0.26$ & $0.0197 * *$ \\
\hline
\end{tabular}

${ }^{\mathrm{A}}$ significantly different from contralateral leg of same total knee replacement group, ${ }^{\mathrm{B}}$ significantly different from same leg of satisfied total knee replacement group, ${ }^{\text {C }}$ significantly different from same leg of healthy group, ${ }^{\#}$ limb main effect,

${ }^{*}$ group main effect, ${ }^{* *} p$ values significant at 0.05 
limb. The dissatisfied group reported increased knee pain in their replaced knees compared with their non-replaced knee and satisfied and healthy groups during all balance tests (except for unilateral balance on the non-replaced static trials; see Table 5). Pain scores for all tests can be found in Table 5 .

\section{Discussion}

The purpose of this study was to examine differences in strength and balance between dissatisfied and satisfied TKR patients. Our hypothesis related to reductions in knee extension strength for the replaced limbs of the dissatisfied group was partially confirmed as the dissatisfied group showed reductions in peak knee extension torque at $180 \%$ s of the replaced limbs compared with their non-replaced limbs and those of the satisfied and healthy groups. The limb main effect for knee extension during the $60 \%$ s test showed reduced extension strength for the replaced limbs compared with the non-replaced limbs, offering partial support for our hypothesis. Additionally, the decreased peak flexion torque in the dissatisfied group replaced limb at $60 \%$ s compared with the satisfied group also provided partial confirmation of our hypothesis. Postoperative increases in knee extensor and flexor strength have been related to improvements in balance and restoration of functional abilities [27-29]. It has been suggested that knee extensor strengthening exercises should continue long-term to improve patient satisfaction and restore functional abilities [30]. Decreased concentric strength in the knee extensors has been linked to decreased stair climbing abilities [27], which is in partial agreement with the results of this study. The dissatisfied group showed increased stair ascent and descent times compared with the satisfied and healthy groups while having reduced knee extensor strength at $180 \%$ in their replaced limb. The replaced limbs presented lower peak extension torque compared with the non-replaced limbs at $60 \%$ s. This imbalance in the dissatisfied group (30\% strength increase in the non-replaced limb compared with the replaced limb) is substantially larger than that in the satisfied group (12\% strength increase in non-replaced limb), which could render stair climbing more difficult (with only a $4 \%$ difference between dominant and non-dominant limbs for the healthy group). Our results of knee extensor and flexor peak torque differences at both $180 \%$ and $60 \%$ are in partial agreement with previous research which has shown peak torque reductions in TKR patients compared with healthy controls for both knee extensors and flexors at $180 \%$ s but not $60 \%$ [15].
While not all results were statistically significant, it is worth noting that average peak torque values across the groups and limbs were always lower in the dissatisfied group compared with the satisfied and healthy groups, for both the replaced and non-replaced limbs. It can be generally concluded that reduced strength is present in the dissatisfied TKR population.

The reductions in strength levels may be in part related to the increased pain levels present in the dissatisfied group. Pain relief and subsequent restoration of activity abilities have been highly correlated with increasing patient satisfaction [28]. Daily activities with increased difficulty often require increased knee flexion and extension, which means that there is a need for increased quadriceps and hamstring strength [29]. This can be further confounded when asymmetries exist. Limb loading asymmetries can occur early after surgery and have been shown to contribute to increased stair climbing times [31]. These reductions in functional abilities have been speculated as being related to pain and quadriceps weakness, both of which were present in our dissatisfied population. Quadriceps weakness is often a point of interest during the rehabilitation process. An increase in the strength levels with a subsequent increase in knee ROM have been evident with increased patient satisfaction [18], although this same study did not show any differences in WOMAC pain and function scores associated with the strength and ROM gains. It should be noted that this previous study [18] did not group the patients depending on their satisfaction as has been done in the current study. The current study showed reductions in passive knee ROM for the dissatisfied group in their replaced limb compared with all other groups and respective limbs, except for the replaced limb of the satisfied group. In addition, the increased WOMAC total and sub-scale scores of dissatisfied group replaced limbs indicate increased deterioration.

No significant differences were present in both the static and dynamic balance levels and limbs, aside from slight increases in mediolateral stability in the replaced limb compared with the non-replaced limb. This was not in agreement with our hypothesis. This result may be due to the inability of a significant number of patients to complete the balance trials, which impacted on the possibility to include their numbers in the statistical analysis. During the unilateral static balance test, $33 \%$ of dissatisfied patients were unable to complete the tests on both their replaced and nonreplaced limbs, which is an increase over the $13 \%$ and $20 \%$ of the satisfied group on their replaced and nonreplaced limbs, respectively. As the difficulty increased 
to the dynamic unilateral stability test, these numbers elevated to $56 \%$ of dissatisfied and $27 \%$ of satisfied patients. This may be in part related to replacement design types received by our patients in the study. Most of the participants had cruciate retaining TKR designs, which do not contain a cam-post mechanism. Longer cam-post designs aid frontal plane stability to the replaced knee joint [32]. Without this added stability, the replaced knees are left to be controlled by musculature and ligaments, some of which (knee musculature) has been shown as reduced in the dissatisfied patients. Further research is warranted to examine the effects of different TKR design types on patient balance ability. With these reduced numbers of patients who were unable to complete the tests, our sample sizes for the statistical analysis were greatly reduced. This likely skewed results of the balance tests as no differences were reported when the patient was able to complete the trials. A completion rate of less than $50 \%$ for the dissatisfied patients is quite low, although the difficulty level was set at a low level (level 11) in the unilateral dynamic balance test. The inability to perform the balance tests may have also contributed to the patient dissatisfaction. Additionally, pain levels were increased for the replaced limb of the dissatisfied participants compared with the satisfied and healthy groups. Improvements in balance have been associated with improvements in gait speed, chair rise tests, and stair climb tests [21]. The presence of pain may not be enough to impact on the balance abilities at the difficulty levels tested here when patients were able to complete the test. However, the subsequent improvements in stair climbing were not evident in this research. Strength and balance are frequently connected since strength is necessary to maintain balance. Increased knee extensor strength coupled with an increased gait speed led to increased anteroposterior balance, but increased knee extensor strength with a reduced gait speed led to a reduced anteroposterior balance [22]. This was not evident with the dissatisfied group as no anteroposterior differences were evident. Other research has shown that peak torque did not predict single-limb balance [23], which does agree with the results of this research since strength differences were evident but balance differences were not.

The consistent issue with the dissatisfied patients is the presence of pain, which subsequently seems to influence certain physical abilities. Increased patient dissatisfaction has been associated with increased pain during activities, lower knee function post-operatively, and depressive symptoms or somatization dysfunction [33]. Treating the psychological factors associat- ed with the surgery may help to improve outcomes. Patients with somatization dysfunction have a 2-fold increase in risk for dissatisfaction with their TKR [33]. This may suggest 1 of 2 options. First, pre-operative psychological screening may help with the rehabilitation of TKR patients as certain psychological needs can be addressed in conjunction with the physical needs. Second, psychological tools to deal with pain management may help to improve functional ability. Multivariate logistic and linear regression models have suggested that dissatisfaction is largely associated with the pain reductions and functional improvements experienced during the first 3 months post-operatively, suggesting that the decision to have surgery should be based on functional limitations, not high pain scores [34]. However, given that pain is present and may continuously impair functional abilities, it should be addressed during rehabilitation processes. Tools such as guided imagery may help to lower pain and anxiety experienced post-operatively [35]. A reduction in pain experienced by dissatisfied patients may help improve their functional abilities and subsequently increase their satisfaction levels. Given the physical and timebased investment in an operation such as a TKR, it is beneficial to address all issues which may improve outcomes.

This study has some limitations. First, the classification of the patient satisfaction and dissatisfaction is subjective in nature; satisfaction is likely a multifaceted response based on factors such as personal experience, bias, and perception, none of which were captured in this study. A simple question was posed to the patients about their perception of their replaced limb, without qualifying whether the satisfaction was based on pain, functional ability, or any other characteristics. As mentioned earlier, the balance results are to be interpreted with caution given the small sample sizes due to the inability of some dissatisfied patients to complete the test. Finally, while patients were asked to perform isokinetic tests with maximum effort, there may have been some reduced performances because of the presence of pain. With pain, while these results appeared to be the individuals' maximum efforts, they may not reflect their true muscular abilities. More research needs to further determine the mechanisms contributing to patient dissatisfaction and subsequent ways to improve them. This may be achieved through longitudinal tracking of patient satisfaction in an attempt to identify both the physical and psychological factors as they occur over time. 


\section{Conclusions}

Patient dissatisfaction is a complex construct that is evidently multifaceted. Throughout all tests, pain was evident, regardless of changes in function. Strength deficits were apparent for the dissatisfied patients in both the knee flexors and extensors. Balance abilities were also reduced through an inability to successfully balance on $1 \mathrm{limb}$, although when this was possible, no differences were evident between groups who were able to complete the unilateral balance tests. Increased selfreported difficulty with certain activities among dissatisfied patients was evident through an imbalance during strength tests, whereby dissatisfied patients exhibited an increased dependence on their non-replaced limb. An increase in strength may provide a more symmetrical movement pattern and therefore better function. This may improve patient satisfaction.

\section{Acknowledgements}

The authors wish to thank the International Society of Biomechanics for their financial support for this project through the Matching Dissertation Grant.

\section{Disclosure statement}

No author has any financial interest or received any financial benefit from this research.

\section{Conflict of interest}

The authors state no conflict of interest.

\section{References}

1. Felts E, Parratte S, Pauly V, Aubaniac J-M, Argenson J-N. Function and quality of life following medial unicompartmental knee arthroplasty in patients 60 years of age or younger. Orthop Traumatol Surg Res. 2010;96(8): 861-867; doi: 10.1016/j.otsr.2010.05.012.

2. Weiss JM, Noble PC, Conditt MA, Kohl HW, Roberts S, Cook KF, et al. What functional activities are important to patients with knee replacements? Clin Orthop RelatRes.2002;404:172-188; doi:10.1097/00003086200211000-00030.

3. Beswick AD, Wylde V, Gooberman-Hill R, Blom A, Dieppe P. What proportion of patients report long-term pain after total hip or knee replacement for osteoarthritis? A systematic review of prospective studies in unselected patients. BMJ Open. 2012;2(1):e000435; doi: 10.1136/bmjopen-2011-000435.

4. Noble PC, Gordon MJ, Weiss JM, Reddix RN, Conditt MA, Mathis KB. Does total knee replacement restore normal knee function? Clin Orthop Relat Res. 2005; 431:157-165; doi: 10.1097/01.blo.0000150130.03519.fb.

5. Boonstra MC, De Waal Malefijt MC, Verdonschot N. How to quantify knee function after total knee arthro- plasty? Knee. 2008;15(5):390-395; doi: 10.1016/j. knee.2008.05.006.

6. Ouellet D, Moffet H. Locomotor deficits before and two months after knee arthroplasty. Arthritis Rheum. 2002; 47(5):484-493; doi: 10.1002/art.10652.

7. Ali A, Sundberg M, Robertsson O, Dahlberg LE, Thorstensson CA, Redlund-Johnell I, et al. Dissatisfied patients after total knee arthroplasty: a registry study involving 114 patients with 8-13 years of follow-up. Acta Orthop. 2014;85(3):229-233; doi: 10.3109/17453674. 2014.916487.

8. Anderson JG, Wixson RL, Tsai D, Stulberg SD, Chang RW. Functional outcome and patient satisfaction in total knee patients over the age of 75. J Arthroplasty. 1996; 11(7):831-840; doi: 10.1016/s0883-5403(96)80183-5.

9. Baker PN, van der Meulen JH, Lewsey J, Gregg JH, National Joint Registry for England and Wales. The role of pain and function in determining patient satisfaction after total knee replacement: data from the National Joint Registry for England and Wales. J Bone Joint Surg Br.2007;89(7):893-900;doi:10.1302/0301-620X.89B7. 19091.

10. Kim TK, Kwon SK, Kang YG, Chang CB, Seong SC. Functional disabilities and satisfaction after total knee arthroplasty in female Asian patients. J Arthroplasty. 2010;25(3):458-464.e2; doi:10.1016/j.arth.2009.01.018.

11. Costigan PA, Deluzio KJ, Wyss UP. Knee and hip kinetics during normal stair climbing. Gait Posture. 2002; 16(1):31-37; doi: 10.1016/s0966-6362(01)00201-6.

12. Judd DL, Eckhoff DG, Stevens-Lapsley JE. Muscle strength loss in the lower limb after total knee arthroplasty. Am J Phys Med Rehabil. 2012;91(3):220-226, quiz 227-230; doi: 10.1097/PHM.0b013e3182411e49.

13. Schroer WC, Diesfeld PJ, Reedy ME, LeMarr AR. Isokinetic strength testing of minimally invasive total knee arthroplasty recovery. J Arthroplasty. 2010;25(2): 274-279; doi: 10.1016/j.arth.2008.09.017.

14. Yoshida Y, Mizner RL, Ramsey DK, Snyder-Mackler L. Examining outcomes from total knee arthroplasty and the relationship between quadriceps strength and knee function over time. Clin Biomech. 2008;23(3):320328; doi: 10.1016/j.clinbiomech.2007.10.008.

15. Bolanos AA, Colizza WA, McCann PD, Gotlin RS, Wootten ME, Kahn BA, et al. A comparison of isokinetic strength testing and gait analysis in patients with posterior cruciate-retaining and substituting knee arthroplasties. J Arthroplasty. 1998;13(8):906-915; doi: 10.1016/s0883-5403(98)90198-x.

16. Rodgers JA, Garvin KL, Walker CW, Morford D, Urban J, Bedard J. Preoperative physical therapy in primary total knee arthroplasty. J Arthroplasty. 1998; 13(4):414-421; doi: 10.1016/s0883-5403(98)90007-9.

17. Rossi MD, Brown LE, Whitehurst M, Charni C, Hankins J, Taylor CL. Comparison of knee extensor strength between limbs in individuals with bilateral total knee replacement. Arch Phys Med Rehabil. 2002;83(4):523526; doi: 10.1053/apmr.2002.30935. 
18. Collados-Maestre I, Lizaur-Utrilla A, Gonzalez-Navarro B, Miralles-Muñoz FA, Marco-Gomez L, LopezPrats FA, et al. Better functional outcome after singleradius TKA compared with multi-radius TKA. Knee Surg Sports Traumatol Arthrosc. 2017;25(11):35083514; doi: 10.1007/s00167-016-4273-0.

19. Swinkels A, Newman JH, Allain TJ. A prospective observational study of falling before and after knee replacement surgery. Age Ageing. 2009;38(2):175-181; doi: 10.1093/ageing/afn229.

20. Gauchard GC, Vançon G, Meyer P, Mainard D, Perrin PP. On the role of knee joint in balance control and postural strategies: effects of total knee replacement in elderly subjects with knee osteoarthritis. Gait Posture. 2010; 32(2):155-160; doi: 10.1016/j.gaitpost.2010.04.002.

21. Liao C-D, Lin L-F, Huang Y-C, Huang S-W, Chou L-C, Liou T-H. Functional outcomes of outpatient balance training following total knee replacement in patients with knee osteoarthritis: a randomized controlled trial. Clin Rehabil. 2015;29(9):855-867; doi: 10.1177/02692 15514564086.

22. Pua Y-H, Liang Z, Ong P-H, Bryant AL, Lo N-N, Clark RA. Associations of knee extensor strength and standing balance with physical function in knee osteoarthritis. Arthritis Care Res. 2011;63(12):1706-1714; doi: 10.1002/acr.20615.

23. Cho SD, Hwang CH. Improved single-limb balance after total knee arthroplasty. Knee Surg Sports Traumatol Arthrosc. 2013;21(12):2744-2750; doi: 10.1007/s00167 -012-2144-x.

24. Standifird TW, Saxton AM, Coe DP, Cates HE, Reinbolt JA, Zhang S. Influence of total knee arthroplasty on gait mechanics of the replaced and non-replaced limb during stair negotiation. J Arthroplasty. 2016;31(1): 278-283; doi: 10.1016/j.arth.2015.06.052.

25. Bellamy N, Buchanan WW, Goldsmith CH, Campbell J, Stitt LW. Validation study of WOMAC: a health status instrument for measuring clinically important patient relevant outcomes to antirheumatic drug therapy in patients with osteoarthritis of the hip or knee. J Rheumatol. 1988;15(12):1833-1840.

26. Behrend H, Giesinger K, Giesinger JM, Kuster MS. The "forgotten joint" as the ultimate goal in joint arthroplasty: validation of a new patient-reported outcome measure. J Arthroplasty. 2012;27(3):430-436.e1; doi: 10.1016/j.arth.2011.06.035.

27. Bade MJ, Kohrt WM, Stevens-Lapsley JE. Outcomes before and after total knee arthroplasty compared to healthy adults. J Orthop Sports Phys Ther. 2010;40(9): 559-567; doi: 10.2519/jospt.2010.3317.

28. Furu M, Ito H, Nishikawa T, Nankaku M, Kuriyama S, Ishikawa M, et al. Quadriceps strength affects patient satisfaction after total knee arthroplasty. J Orthop Sci. 2016;21(1):38-43; doi: 10.1016/j.jos.2015.10.002.

29. Ward TR, Burns AW, Gillespie MJ, Scarvell JM, Smith PN. Bicruciate-stabilised total knee replacements produce more normal sagittal plane kinematics than posterior-stabilised designs. J Bone Joint Surg Br. 2011;93(7):907-913; doi: 10.1302/0301-620X.93B7. 26208.

30. Ishii Y, Noguchi H, Sato J, Sakurai T, Toyabe S-I. Quadriceps strength impairment in the mid- to longterm follow-up period after total knee arthroplasty. Knee Surg Sports Traumatol Arthrosc. 2017;25(11): 3372-3377; doi: 10.1007/s00167-016-4333-5.

31. Christiansen CL, Bade MJ, Judd DL, Stevens-Lapsley JE. Weight-bearing asymmetry during sit-stand transitions related to impairment and functional mobility after total knee arthroplasty. Arch Phys Med Rehabil. 2011;92(10):1624-1629; doi: 10.1016/j.apmr.2011.05. 010.

32. Williams DH, Garbuz DS, Masri BA. Total knee arthroplasty: techniques and results. B C Med J. 2010;52(9): 447-454.

33. Bierke S, Häner M, Petersen W. Influence of somatization and depressive symptoms on the course of pain within the first year after uncomplicated total knee replacement: a prospective study. Int Orthop. 2016; 40(7):1353-1360; doi: 10.1007/s00264-015-3105-z.

34. Huijbregts HJTAM, Khan RJK, Fick DP, Jarrett OM, Haebich S. Prosthetic alignment after total knee replacement is not associated with dissatisfaction or change in Oxford Knee Score: a multivariable regression analysis. Knee. 2016;23(3):535-539; doi: 10.1016/ j.knee.2015.12.007.

35. Thomas KM, Sethares KA. Is guided imagery effective in reducing pain and anxiety in the postoperative total joint arthroplasty patient? Orthop Nurs. 2010;29(6): 393-399; doi: 10.1097/NOR.0b013e3181f837f0. 